Uşak Üniversitesi Sosyal Bilimler Dergisi

$2015,8 / 3$

\title{
Fiziksel Özellikler Açısından İdeal Stoneware Bünyelerin Araştırılması
}

Ensar TAÇYILDIZ*

\section{Öz}

Stoneware bünyeler standart bir formüle sahip olmamalarına rağmen, doğal kil, kaolen ve feldispatik minerallerden hareketle üretilirler. oluşurlar. Seramik ürünlerin fiziksel özelliklerini etkileyen en önemli faktörler; ilgili hammaddelerin tane boyutu, reçete bileşimi ve pişme sıcaklığıdır. Bu çalışmada, stoneware bünyelerin fiziksel özelliklerine kuvars, kaolen ve nefelin syenitin miktarlarının $1200^{\circ} C^{\prime}$ de yapılan pişirme sonucu etkileri araştırılmıştır.

Stoneware bünyelerin fiziksel özelliklerine hammadde miktarının etkisini belirlemek amacıyla, deneysel çalışmalar üç grupta yürütülmüştür; Birinci grupta, kuvars miktarının ve ikinci grup çalışmalarda kaolin miktarının etkileri incelenmiştir. Üçüncü grupta kaolen ve kil miktarı sabit tutularak, kuvars miktarı azaltılmış, nefelin syenit miktarı artırılmıştır. Sonular değerlendirilerek uygun nitelikte stoneware bünyeler geliştirilmiştir.

Anahtar Kelimeler: Stoneware Bünyeler, Nefelin Siyenit, Kaolin, Kuvars, Fiziksel Özellikler.

\section{Investigation of Optimal Stoneware Bodies in terms of Physical Properties}

\begin{abstract}
Stoneware bodies have no standart body formulations, however consist of naturally occuring clay, kaolin and feldspatic minerals. The most important factors which affect the physical properties of ceramic products were the chemical composition and firing temperature. In this study, the effects of quartz, kaolin and nepheline syenite level on the physical properties of the stoneware bodies fired at $1200^{\circ} \mathrm{C}$ were investigated.

In order to determine such effects of starting of raw meterials on the pysical properties of stoneware bodies, experimental studies were performed in three grups. In grup one the effect of quartz was investigated. In grup two the effect of kaolin was studied. In the third grup, the investigation centered on the effect of nepheline syenite; the amount of quartz was reduced and nepheline syenite was increased while amounts of
\end{abstract}

* Doç., Dr., Anadolu Üniversitesi, Porsuk Meslek Yüksekokulu, Seramik Bölümü 
kaolin and clay were kept constant. The results of these investigation led to the optimal body formulation of stoneware.

Key Words: Stoneware Bodies, Nepheline Syenite, Kaolin, Quartz, Physical Properties.

\section{Giriş}

Stoneware bünyeler hem endüstriyel hem de sanat seramiği üretiminde kullanılmaktadır. Bu bünyeler standart bir formülasyona sahip olmamalarına rağmen, karakterize edilerek çeşitli şekillendirme yöntemlerine uygun hâle hale getirilebilir. Türüne bağlı olarak genellikle, 1200-1300 ${ }^{\circ} \mathrm{C}^{\prime}$ de sinterleşen, su emmesi \% 0-4 aralığında değişen ve pişme mukavemeti yüksek olan bünyelerdir (Ryan and Radford, 1987: 51; Hlavac, 1983: 313).

Stoneware bünyelerin üretiminde plastik killer, kuvars ve feldispatik mineraller kullanılmaktadır. Seramik üretiminde, nihai ürünün fiziksel özelliklerini etkileyen en önemli faktörler; bünyeyi oluşturan hammaddelerin tane boyutu, reçete bileşimi ve pişirme sıcaklığıdır. Kil grubu mineraller çamura şekillendirebilme (plastisite) özelliği kazandırarak şekillendirmeyi kolaylaştırır. Şekil değişikliğine (deformasyona) uğramaksızın kurumasını ve pişirilmesini sağlar. Feldispatik mineraller pişme sırasında, camsı faz oluşturarak su emme özelliğini düşürür. Kuvars ise diğer hammaddelere göre yüksek ergime derecesiyle yapıda iskelet görevi görür ve pişirme esnasında şekil değişikliğini önler. Bu hammaddeler kullanılarak farklı fiziksel özelliklere sahip stoneware bünyeler üretilmektedir.

Kullanılan hammaddelerin özelliklerine bağlı olarak, stoneware bünyelerin pişme rengi krem- kahve- siyah aralığında olabilir. Bünyelerin pişme rengini etkileyen iki faktör vardır; birincisi bünyede kullanılan hammaddeler içerisinde yer alan metalik oksitler, ikincisi ise pişirme atmosferidir (Chappell, 1991: 62).

$\mathrm{Bu}$ çalışmada, $1200^{\circ} \mathrm{C}^{\prime}$ de pişirilen, su emmesi ve mukavemeti yüksek stoneware bünyelerin hazırlanması hedeflenmiştir. Bilindiği gibi şekillendirme yöntemi, çamur özelliklerini belirleyen unsurlardan biridir. Mevut çalışmada dökümle şekillendirme esas alınmış, kaolen-nefelin siyenit-kuvars miktarının stoneware bünye üzerine etkilerini araştırmak amacıyla çeşitli reçeteler hazırlanıp, test edilerek, her bir hammaddenin etkisi deneysel olarak ortaya konulmuştur. Sonuçlardan hareketle ideal stoneware bünyeler elde edilmiştir. 


\section{Malzeme ve Yöntem}

Stoneware bünyelerin fiziksel özelliklerine kuvars, kaolen ve feldispat miktarlarının etkilerinin araştırıldığı bu çalışmada, kullanılan hammaddeler yerli hammaddeler olup, kimyasal analizleri Çizelge 1'de, kaolin ve killere ait fiziksel özellikler ise Çizelge 2 'de verilmiştir. Stoneware bünyelerin fiziksel özelliklerine hammadde miktarlarının etkilerinin araştırmak amacıyla yapılan deneysel çalışmalar üç grup olarak planlanmıştır.

Birinci grupta, kaolen miktarının etkilerini araştırmak amacıyla, reçete bileşiminde kuvars ve kil sabit tutulmuş, nefelin azaltılarak kaolen attırılmıştır. Bu gurup reçeteler, kaolence zengin karışımlar olarak adlandırılmıştır.

İkici grupta, kuvars miktarının etkisini araştırmak amacıyla, reçete bileşiminde feldispat ve kil miktarı sabit tutulmuş, kaolen azaltılarak kuvars attırılmıştır. $\mathrm{Bu}$ gurup reçeteler, kuvarsca zengin karışımlar olarak isimlendirilmiştir.

Üçüncü grupta ise, nefelin miktarının etkisini araştırmak amacıyla, reçete bileşiminde kaolen ve kil sabit tutulmuş, kuvars azaltılarak nefelinin bünye özelliklerine etkileri araştırılmıştır. Bu gurup reçeteler, nefelince zengin karışımlar olarak adlandırılmıştır. Hazırlanan karışımların fiziksel özellikleri değerlendirilmiş, fiziksel özelliklerden bazılarının ideal özellikler açısından uygun olmadığı belirlenmiştir. Dolayısıyla, bu çalışmalara ek olarak, ideal stoneware bünye çalışmaları yapılmıştır.

Hazırlanan reçeteler $2 \mathrm{~kg}$ kuru hammadde kapasiteli porselen değirmende 5 saat süreyle öğütülmüştür. Öğütme işleminde $2 \mathrm{~kg}$ hammadde, $2 \mathrm{~kg}$ porselen bilye, $800 \mathrm{ml} \mathrm{su}, 7 \mathrm{ml}$ sodyum silikat ve 3,5 gr soda kullanılmıştır. Değirmenin dönüş hızı 60 d/dk olarak seçilmiş olup, öğütme sonrası her numune 100 meşlik elekten geçirilmiştir.

Deney numunelerinin hazırlanmasında alçı kalıplar kullanılmış olup, alçı-su oranı 100/70 olarak seçilmiştir. Numunelerin pişirme işlemi kamera tipi elektrikli fırında $1200^{\circ} \mathrm{C}^{\prime}$ de gerçekleştirilmiştir. 
Çizelge 1. Kullanılan Hammaddelerin Kimyasal Analizi

\begin{tabular}{lcccccc} 
\% & Kil 1 & Kil 2 & Kil 3 & Kaolin & N.Syeni & Kuvars \\
\hline $\mathrm{SiO}_{2}$ & 58,40 & 55,95 & 59,00 & 64,40 & 59,90 & 98,30 \\
$\mathrm{Al}_{2} \mathrm{O}_{3}$ & 27,82 & 28,46 & 29,09 & 23,00 & 23,80 & 0,26 \\
$\mathrm{Fe}_{2} \mathbf{O}_{3}$ & 1,60 & 1,60 & - & 0,90 & 0,08 & 0,02 \\
$\mathrm{TiO}_{2}$ & 1,00 & 1,06 & - & 0,20 & - & - \\
$\mathrm{CaO}$ & 0,30 & 0,62 & 1,50 & 1,10 & 0,70 & 0,05 \\
$\mathrm{MgO}$ & 0,13 & 0,38 & - & 1,20 & 0,20 & 0,20 \\
$\mathbf{N a} 2 \mathbf{O}$ & 0,43 & 0,42 & - & 0,70 & 10,02 & 0,58 \\
$\mathbf{K}_{2} \mathbf{O}$ & 1,37 & 2,58 & 2,41 & 2,70 & 4,60 & 0,29 \\
${ }^{*} \mathbf{A . K}$ & 8,95 & 9,11 & 8,00 & 5,80 & 0,70 & 0,30 \\
\hline
\end{tabular}

${ }^{*}$ A:K: Ateş kaybı

Çizelge 2. Kullanılan Kil-Kaolenin Fiziksel Özellikleri

\begin{tabular}{lcccc} 
Fiziksel Özellikler & Kil 1 & Kil 2 & Kil 3 & Kaolin \\
\hline Kuru Çekme (\%) & 4,16 & 6,37 & 6,98 & 3,08 \\
Pişme Çekmesi (\%) & 4,79 & 8,51 & 9,02 & 4,04 \\
Toplu Çekme (\%) & 8,61 & 14 & 15,41 & 7,02 \\
Su Emme (\%) & 12,3 & 2,7 & 1,96 & 19,32 \\
Kuru Mukavemet $\left(\mathrm{kg} / \mathrm{cm}^{2}\right)$ & 18,84 & 21,96 & 22,71 & 13,92 \\
Pişme Mukavemeti $\left(\mathrm{kg} / \mathrm{cm}^{2}\right)$ & 189,5 & 179,66 & 191,36 & 47,96 \\
Yoğruma Suyu (\%) & 35,7 & 41,34 & 46,42 & 28,36 \\
\hline
\end{tabular}

\section{Bulgular ve Değerlendirme}

\subsection{Kaolen Miktarının Stoneware Bünye Üzerine Etkileri}

Stoneware bünyelerin fiziksel özelliklerine kaolen miktarının etkilerini araştırmak amacıyla hazırlanan karışımların reçete bileşimi Çizelge 3'de, fiziksel özellikleri de Çizelge 4'de verilmiştir.

Çizelge 3. Kaolence Zengin Karışımların Reçete Bileşimleri

\begin{tabular}{lcccc}
\multicolumn{5}{c}{ Reçete Bileşimi \% } \\
\hline Hammaddeler & No.1 & No.2 & No.3 & No.4 \\
\hline Kaolen & 10 & 30 & 50 & 70 \\
Kil 1 & 5 & 5 & 5 & 5 \\
Kil 2 & 5 & 5 & 5 & 5 \\
Kil 3 & 10 & 10 & 10 & 10 \\
N. Siyenit & 70 & 50 & 30 & 10 \\
Kuvars & --- & --- & --- & --- \\
\hline
\end{tabular}


Sosyal Bilimler Dergisi 25

Çizelge 4. Kaolence Zengin Karışımların Fiziksel Özellikleri

\begin{tabular}{lcccc} 
Fiziksel Özellikler & No.1 & No.2 & No.3 & No.4 \\
\hline Kuru Çekme (\%) & 0,91 & 1,96 & 2,25 & 2,82 \\
Pişme Çekmesi (\%) & 12,46 & 11,10 & 10 & 8,00 \\
Toplu Çekme (\%) & 13,15 & 12,82 & 12,05 & 10,61 \\
Su Emme (\%) & 0,02 & 0,07 & 2,39 & 12,56 \\
Kuru Mukavemet $\left(\mathrm{kg} / \mathrm{cm}^{2}\right)$ & 3,65 & 8,92 & 12,24 & 14,08 \\
Pişme Mukavemeti $\left(\mathrm{kg} / \mathrm{cm}^{2}\right)$ & 312,78 & 290,22 & 219,76 & 187,24 \\
Deformasyon (mm) & 64,72 & 60,45 & 29,87 & 12,87 \\
Yoğrulma Suyu (\%) & 20,51 & 26,25 & 32,15 & 36,72 \\
Döküm Hızı (mm²/dk) & 1,96 & 0,86 & 0,48 & 0,27 \\
Viskozite (sn) & 21 & 20 & 22 & 22 \\
Litre Ağırlığ1 (gr) & 1700 & 1690 & 1700 & 1710 \\
\hline
\end{tabular}

Çizelge 4'den görüldüğü gibi, nefelin siyenit miktarı azaltılıp, kaolen miktarı arttıkça boyutça çekme, pişme mukavemeti, deformasyon, döküm hızı azalmış; kuru mukavemet ve yoğrulma suyu artmıştır. Kaolin özlü bir hammadde olup ergime derecesi yüksek bir malzemedir. Kaolin miktarının reçete bileşiminde artırılması, karışımdaki $\mathrm{SiO}_{2}$ oranını artırmaktadır. Buna paralel olarak, nefelin siyenit miktarının azaltılması ile yüksek sıcaklıkta taneler arasındaki gözenekleri dolduracak camsı faz miktarı azalmaktadır. Dolayısıyla kaolen miktarının reçete bileşiminde artması, nefelin siyenit miktarının azalması sonucunda, boyutça çekme, pişme mukavemeti, deformasyon azalmıs; su emme, kuru mukavemet ve yoğrulma suyu artmıştır. Döküm hızındaki azalma, kaolinin tabakalı bir yapıya sahip olması, alçı kalıbın gözeneklerini kapatarak geçirimsiz bir ara yüzey oluşturmasından kaynaklanmaktadır (Dimanch vd, 1994: 184).

\subsection{Kuvars Miktarının Stoneware Bünye Üzerine Etkileri}

Stoneware bünyelerin fiziksel özelliklerine kuvars miktarının etkilerini araştırmak amacıyla hazırlanan karışımların reçete bileşimi Çizelge 5'de, fiziksel özellikleri ise Çizelge 6'da sunulmuştur. 
Çizelge 5. Kuvarsca Zengin Karışımların Reçete Bileşimleri

Reçete Bileşimi \%

\begin{tabular}{lcccc}
\hline Hammaddeler & No.1 & No.2 & No.3 & No.4 \\
\hline Kuvars & --- & 20 & 40 & 60 \\
Kaolen & 70 & 50 & 30 & 10 \\
N.Siyenit & 10 & 10 & 10 & 10 \\
Kil 1 & 5 & 5 & 5 & 5 \\
Kil 2 & 5 & 5 & 5 & 5 \\
Kil 3 & 10 & 10 & 10 & 10 \\
\hline
\end{tabular}

Çizelge 6. Kuvarca Zengin Karışımların Fiziksel Özellikleri

\begin{tabular}{lcccc} 
Fiziksel Özellikler & No.1 & No.2 & No.3 & No.4 \\
\hline Kuru Çekme (\%) & 2,82 & 2,40 & 1,26 & 0,76 \\
Pişme Çekmesi(\%) & 8,00 & 4,30 & 2,78 & 1,45 \\
Toplu Çekme (\%) & 10,61 & 6,80 & 4,02 & 2,21 \\
Su Emme (\%) & 12,56 & 14,82 & 18,15 & 21,8 \\
Kuru Mukavemet $\left(\mathrm{kg} / \mathrm{cm}^{2}\right)$ & 14,08 & 8,95 & 7,65 & 3,21 \\
Pişme Mukavemeti $\left(\mathrm{kg} / \mathrm{cm}^{2}\right)$ & 187,24 & 134,78 & 116,67 & 89,92 \\
Deformasyon (mm) & 12,87 & 9,96 & 6,50 & 2,94 \\
Yoğrulma Suyu (\%) & 36,72 & 27,89 & 21,89 & 19,28 \\
Döküm Hızı (mm²/dk) & 0,27 & 0,42 & 0,67 & 1,76 \\
Viskozite (sn) & 22 & 20 & 20 & 21 \\
Litre Ağırlığı (gr) & 1710 & 1700 & 1710 & 1710 \\
\hline
\end{tabular}

Çizelge 6'dan görüldüğü gibi, kaolen miktarı azaltılıp, kuvars miktarı arttıkça boyutça çekme, kuru- pişme mukavemeti, deformasyon, yoğrulma suyu azalmış; su emme ve döküm hızı artmıştır. Kuvars özsüz bir hammadde olup, ergime derecesi yüksektir. Dolayısıyla, kuvars miktarının reçete bileşiminde artırılması, kaolen miktarının azaltılması ile yüksek sıcaklıkta taneler arasındaki gözenekleri dolduracak camsı faz miktarı giderek azalmış, ürün giderek daha gözenekli bir hal almıştır. Dolayısıyla, su emme artmış, boyutça çekme, kuru-pişme mukavemeti, deformasyon, yoğrulma suyu azalmıştır. Döküm hızındaki artış kuvarsın şekillendirme suyunu kolaylıkla kaybetmesi nedeniyledir. Ancak şunu da belirtmek gerekir ki, reçete içinde kuvars miktarı artıkça, döküm kalınlığı tabanda ve cidarlarda farklıklar göstermektedir. Bunun nedeni ise kuvarsın özsüz bir malzeme olması, uzun süre yapıda askıda kalamayarak dibe çökmesidir. 


\subsection{Nefelin Siyenit Miktarının Stoneware Bünye Üzerine Etkileri}

Stoneware bünyelerin fiziksel özelliklerine nefelin siyenit miktarının etkilerini araştırmak amacıyla hazırlanan karışımların reçete bileşimi Çizelge 7'de, fiziksel özellikleri ise Çizelge 8'de verilmiştir.

Çizelge 7. Nefelince Zengin Karışımların Reçete Bileşimleri

Reçete Bileşimi \%

\begin{tabular}{lcccc}
\hline Hammaddeler & No.1 & No.2 & No.3 & No.4 \\
\hline N. Siyenit & 10 & 30 & 50 & 70 \\
Kuvars & 60 & 40 & 20 & --- \\
Kaolen & 10 & 10 & 10 & 10 \\
Kil 1 & 5 & 5 & 5 & 5 \\
Kil 2 & 5 & 5 & 5 & 5 \\
Kil 3 & 10 & 10 & 10 & 10 \\
& & & & \\
\hline
\end{tabular}

Çizelge 8. Nefelin Syenitcece Zengin Karışımların Fiziksel Özellikleri

\begin{tabular}{lcccc} 
Fiziksel Özellikler & No.1 & No.2 & No.3 & No.4 \\
\hline Kuru Çekme (\%) & 0,76 & 0,91 & 0,90 & 0,91 \\
Pişme Çekmesi(\%) & 1,45 & 8,06 & 12,18 & 12,46 \\
Toplu Çekme (\%) & 2,21 & 8,91 & 13,14 & 13,15 \\
Su Emme (\%) & 21,8 & 7,12 & 0,10 & 0,02 \\
Kuru Mukavemet $\left(\mathrm{kg} / \mathrm{cm}^{2}\right)$ & 3,21 & 3,5 & 3,44 & 3,65 \\
Pişme Mukavemeti $\left(\mathrm{kg} / \mathrm{cm}^{2}\right)$ & 89,92 & 234,56 & 289,45 & 312,78 \\
Deformasyon (mm) & 2,94 & 39,6 & 48,6 & 64,72 \\
Yoğrulma Suyu (\%) & 19,28 & 19,75 & 20,12 & 20,51 \\
Döküm Hızı (mm $/ \mathrm{dk})$ & 1,76 & 1,7 & 1,78 & 1,96 \\
Viskozite (sn) & 21 & 21 & 21 & 21 \\
Litre Ağırlığı $(\mathrm{gr})$ & 1710 & 1700 & 1700 & 1700 \\
\hline
\end{tabular}

Çizelge 8'den görüldüğg̈ gibi, nefelin siyenit miktarı artırılıp, kuvars miktarı azaltıldıkça boyutça çekme, pişme mukavemeti, deformasyon değerleri artmış, su emme değeri azalmıştır. Kuru mukavemet, döküm hızı ve yoğrulma suyu ise belirgin bir değişim olmamıştır. Nefelin siyenit feldspatik bir hammadde olduğundan, pişirme sırasında $1000^{\circ} \mathrm{C}^{\prime}$ de ergime sürecine başlar ve pişirme sırasında sıcaklığın yükselmesiyle camsı faz oluşturarak yapıda yer alan erimemiş tanelerin etrafını çevreleyerek, kendi erirken eritmeye de başlar. Dolayısıyla, camlaşma (vitrifikasyon) etkisi yaparak sinterleşmeyi sağlar. Camsı faz miktarı arttıkça boyutça çekme, 
pişme mukavemeti artar, su emme azalır. Buna karşın, camsı faz miktarının artması deformasyon miktarını olumsuz yönde etkiler (Kökden ve Özgen, 1994: 327). Nefelin siyenit miktarının artmasıyla, döküm hızı, yoğrulma suyu ve kuru mukavemet değerlerinde belirgin bir değişimin olmamasının nedeni ise reçete bileşiminde özsüz malzeme miktarının değişmemiş olmasidir.

\section{4. İdeal Stoneware Bünyelerin Hazırlanması}

İdeal özellikler içeren stoneware bünyelerin hazırlanmasında Çizelge 4, 6 ve Çizelge 8 'de verilen kaolen, kuvars ve nefelin siyenitçe zengin karışımların fiziksel özelliklerinden faydalanılmıştır. Çizelge 4 . incelendiğinde, kaolen oranının artmasına rağmen, nihai ürünün kuru mukavemetinin çok düşük ve su emmesinin çok yüksek olduğu görülmektedir. Bu nedenle kaolinin tek başına böylesi bünyelerde kuru mukavemeti artırmada ve su emmeyi azaltmada yeterli olmadığ gözlenmektedir. Çizelge 5. incelendiğinde kuvars miktarı artıkça, çekme ve deformasyon azalmasına rağmen, kuru-pişme mukavemeti, yoğrulma suyu giderek azalmış ve su emme büyük oranda artmıştır. Dolayısıyla, bu gurupta yer alan karışımlardan hiçbiri stoneware bünyeler için uygun fiziksel özellikler taşımamaktadır. Çizelge 8 . incelendiğinde nefelin siyenit miktarının \%30'un üzerinde olduğu karışımların deformasyon miktarının önemli ölçüde arttığı gözlenmektedir. Nefelin siyenit miktarının \%10 olduğu karışımın ise su emme ve mukavemet özellikleri nedeniyle stoneware bünyeler için uygun nitelikler göstermediği belirlenmiştir. Dolayısıyla, Çizelge 3'den kaolen miktarının biraz azaltılarak kil miktarının arttırılmasına, kaolen miktarının \% 20, Çizelge 5'den kuvars miktarının \%25 ve Çizelge 7 'den nefelin siyenit miktarının maksimum \%30 oranlarında kullanılabileceği varsayımından hareketle bir baz reçete (Çizelge 9 No.1) oluşturulmuştur. Daha sonraki deneysel çalışmalarda, baz reçeteye göre kaolen ve kuvars miktarı sabit tutulmuş, nefelin siyenit miktarı azaltılarak azalan oranda kil arttırılmıştır.

Çizelge 9. İdeal Stoneware Bünye Karışımların Reçete Bileşimleri

Reçete Bileşimi\%

\begin{tabular}{lcccccc}
\hline Hammaddeler & No.1 & No.2 & No.3 & No.4 & No.5 & No.6 \\
\hline Kaolen & 20 & 20 & 20 & 20 & 20 & 20 \\
Kuvars & 25 & 25 & 25 & 25 & 25 & 25 \\
N. Siyenit & 30 & 28 & 26 & 24 & 22 & 20 \\
Kil 1 & 5 & 5 & 5 & 5 & 5 & 5 \\
Kil 2 & 10 & 10 & 10 & 10 & 10 & 10 \\
Kil 3 & 12 & 14 & 16 & 18 & 20 & 22 \\
\hline
\end{tabular}


Sosyal Bilimler Dergisi 29

Çizelge 10. İdeal Stoneware Bünye Karışımların Fiziksel Özellikleri

\begin{tabular}{lcccccc} 
Fiziksel Özellikler & No.1 & No.2 & No.3 & No.4 & No.5 & No.6 \\
\hline Kuru Çekme (\%) & 2,14 & 2,38 & 2,68 & 3,40 & 3,94 & 4,10 \\
Pişme Çekmesi(\%) & 8,83 & 9,03 & 9,60 & 9,51 & 9,34 & 8,86 \\
Toplu Çekme (\%) & 10,88 & 11,12 & 11,86 & 12,00 & 12,06 & 12,60 \\
Su Emme (\%) & 2,80 & 2,22 & 1,10 & 0,52 & 0,23 & 0,12 \\
Kuru Mukavemet (kg/cm²) & 23,21 & 25,75 & 27,74 & 32,65 & 34,72 & 35,96 \\
Pişme Mukavemeti (kg/cm²) & 282,92 & 297,56 & 301,45 & 312,78 & 319,89 & 326,67 \\
Deformasyon (mm) & 12,94 & 11,06 & 8,6 & 6,47 & 4,12 & 3,91 \\
Yoğrulma suyu (\%) & 26,38 & 28,85 & 30,78 & 33,51 & 35.45 & 37,23 \\
Döküm Hızı (mm²/dk) & 1,76 & 1,72 & 1,78 & 1,86 & 1,97 & 1,92 \\
Viskozite (sn) & 22 & 22 & 22 & 22 & 22 & 22 \\
Litre Ağırlığı (gr) & 1710 & 1700 & 1710 & 1700 & 1710 & 1710 \\
\hline
\end{tabular}

\section{Sonuç ve Öneriler}

Reçete bileşiminde kaolen miktarı artırılıp nefelin siyenit miktarı azaldıkça, çizelge $4^{\prime}$ 'den de görülebileceği gibi, stoneware döküm karışımının kuru mukavemeti, yoğrulma suyu, su emmesi ve kuru çekmesi artmakta, toplu çekmesi, pişme mukavemeti ve döküm hızı azalmaktadır.

Reçete bileşiminde kuvars miktarı artırılıp kaolin miktarı azaldıkça, Çizelge 6'dan da görülebileceği gibi, stoneware döküm karışımları giderek özsüz bir yapı kazanmaktadır. Bu nedenle, döküm karışımında kuvars miktarının \% 50'nin üzerine olduğu karışımlardan, kalıptan ürün almak mümkün olmamaktadır. Ayrıca, karışımda kuvars miktarı artıkça, döküm karışımı kısa sürede kalıp dibine çökmekte ve homojen bir et kalınlığı elde edilememektedir. $\mathrm{Bu}$ olumsuzluklara rağmen ürün bileşiminde kuvars miktarı artıkça, boyutça çekme ve deformasyon azalmaktadır.

Reçete bileşiminde nefelin siyenit miktarı artıkça, Çizelge 8'den de görülebileceği gibi, stoneware döküm karışımlarının boyutça çekmesi, pişme mukavemeti artmıs, su emmesi azalmıştır. Nefelin siyenit miktarının kuru mukavemet ve yoğrulma suyu üzerinde önemli bir etkisinin olmadığ gözlenmiştir. Şekillendirme ve sonrası işlemler açısından bakıldığında, bu iki özelliğin olumsuz etkileri görülmektedir. Şekillendirmede zorluklar yaşanmakta, şekillendirme sonrası ürün kırılgan bir yapı kazanmaktadır. Ayrıca, reçete bileşiminde nefelin siyenit miktarı artıkça deformasyon da önemli ölçüde artmaktadır. Deneysel çalışmalar sonucunda elde edilen 
verilerden bazı fiziksel özelliklerin olumlu olsa da, su emme ve mukavemet özellikleri nedeniyle stoneware bünyeler için uygun özellikler göstermediği belirlenmiştir. Olumsuz fiziksel özellikleri geliştirmek için bir baz reçete Çizelge 10 (No.1) oluşturulmuş ve çalışmalar bu bağlamda sürdürülmüştür. Deneysel çalışmalardan elde edilen sonuçlar değerlendirildiğinde, ideal stoneware reçete çalışmalarından (Çizelge 10) 5 ve 6 nolu reçetelerin stoneware bünyeler için en ideal fiziksel özellikler gösterdiği belirlenmiştir.

\section{Kaynakça}

CHAMPELL, J. (1991). The Potter's Complete Book of Clay and Glazes, New York.

DIMANCH, F. RASSEL, A. TARTE, P. and THOREZ, J. (1994). The Kaolins Mineralogy, Deposites Uses, Min. Engng. Vol.6, (4).

HLAVAC, J. (1983). The technology of Glass and Ceramics, New York.

KÖKDEN, M. ve ÖZGEN, S. (1994). Porselen Reçetesi Geliştirme Çalışmaları, II. Uluslararası Seramik Kongresi Bildiriler Kitabı, Cilt 1, Türk Seramik Der. Yay. No. 10.

RYAN, W. and RADFORD, C. (1987). Whitewares Production Testing and Quality Control, UK. 